\title{
AS TENDÊNCIAS PÓS-MODERNAS EM BUSCA DE COMPENSAÇÕES - O CONTRA-PESO DO MULTICULTURALISMO CRÍTICO ${ }^{1}$
}

Marcos Antonio C. Silva ${ }^{2}$

Resumo: Em tempos de desesperança, é mister romper com os pessimismos, entretanto, é igualmente necessário separar a crítica do romantismo pedagógico. A convivência com embaçamentos entre teorias e práticas educacionais, juntamente com políticas econômicas de empenho duvidoso no campo social, sugere espaços para que recontextualizações apareçam como modismos no mínimo perigosos. Nesse sentido, considerar a abordagem curricular multiculturalista como uma panacéia é um equivoco que precisamos evitar. As contribuições de Peter Mclaren certamente lançam outros desafios para uma leitura crítica das tendências pedagógicas pós-modernas, que permeiam as políticas públicas já há algum tempo, podendo servir como referência na construção de políticas educacionais críticas e de resistência.

Palavras-chave: multiculturalismo, pós-moderno, políticas educacionais. 
A educação vive, já há algum tempo, momentos de desconfiança e suspeição diante das "novas tendências" que permeiam as teorias pedagógicas. Nesse texto, procuro alinhavar algumas teorias situadas numa perspectiva crítica, tentando fazer algumas aproximações para possibilitar reflexões para a prática pedagógica.

Inicialmente, pretendo situar minhas colocações no que Peter Mclaren (1997) denomina de Pós-modernismo Crítico. O autor, professor universitário americano, identificado com os problemas culturais e de "parentesco intelectual" com Paulo Freire (segundo o próprio Paulo Freire), é responsável por diversas obras e, como muitos, sofreu e sofre influências dessas "novas tendências educacionais" disseminadas pelas correntes ditas pós-modernas. Mclaren nos auxilia com suas interpretações sobre as tendências pós-modernas na educação e pode e deve servir para realizarmos algumas pontes com nossa área. Primeiramente, distingue, baseado nas teorias de Teresa Ebert (1991), as concepções pós-modernas em duas: lúdico e de resistência. Segundo Mclaren, "o pós-modernismo lúdico geralmente enfoca o fabuloso potencial combinatório dos signos na produção de significados e se ocupa com uma realidade que é constituída por uma contínua característica "brincalhona" do significante e da heterogeneidade de diferenças" (1997, p.65). Constitui um momento de autoreflexividade na desconstrução das metanarrativas ocidentais, servindo como questionamento principal para as teorizações pós-modernas (Lyotard, Derrida, Baudrillard). Busca desconstruir a maneira como o poder é empregado dentro de cenários culturais, destotalizando as micropolíticas de resistência à dominação, fazendo das lutas políticas apenas cenários de contingências. Percebe-se que a tradução desse ceticismo político pode trazer graves consequências para o campo político-educacional por sua tendência simplista e desesperançosa que, com frequência, reinscreve o status quo e reduz a história à suplementaridade da significação ou à característica flutuante da textualidade (MCLAREN citando EBERT, 1991). O pós-modernismo lúdico (cético ou espectral) lida com a desdiferenciação e a mistura do conhecimento disciplinar e dos gêneros, envolvendo a implosão do real em representação, do social e do valor de troca em valor de signo (Baudrillard). Para o pós-modernismo lúdico, o social é sugado e dissolvido no mundo 
dos signos e da comunicação de massa, e a profundidade do significado é implodida na superficialidade. Como modelo de crítica, assume a tarefa de interrogação constante de enunciações, mas somente nas especificidades locais, falhando em relação às estruturas de dominação maiores e mais relevantes (ARONOWITZ; GIROUX, 1991).

Mclaren apresenta um contra-peso (palavras do autor) ao pós-modernismo lúdico, aliando algumas teorias como pós-modernismo oposicional (FOSTER, 1983), teoria crítica radical (Zavarzadeh e Morton, 1991), Educação Pós-moderna (Aronowitz e Giroux,1992), Pós-modernismo de resistência (Ebert, 1991) E Pós-Modernismo Crítico (Giroux1992, Mclaren e Hammer, 1989). O pós-modernismo de resistência traz à crítica lúdica uma forma de intervenção materialista, uma vez que não está somente embasado em uma teoria textual da diferença, mas em vez disso, em uma teoria que é social e histórica. Em outras palavras, acredita na possibilidade de intervenção e transformação um tanto amortizadas nas teorias lúdicas, politizando as diferenças nos conflitos sociais e históricos reais, em vez de interpretálos como contingências textuais ou semióticas.

Sem ignorar as dimensões sociais e históricas da diferença, o pós-modernismo de resistência, ou crítico, articula uma teoria da diferença na qual a diferenciação, o deferimento e o movimento dos significantes não sejam tomados como o resultado de uma lógica imanente da linguagem, mas como efeito de conflitos sociais que atravessam a significação. Desse modo, o pós-modernismo de resistência tem favorecido novas formas de práxis pedagógicas que se preocupam com o repensar de políticas educacionais em uma sociedade multicultural (ARONOWITZ e GIROUX,1991).

Outra contribuição importante é a concepção de totalidade apresentada pelo pós-modernismo crítico. Diferente da "guerra às totalidades" defendida por Lyotard, Mclaren enfatiza a necessidade de as educadoras afirmarem os conhecimentos sociopolíticos e os posicionamentos éticos "locais" de seus alunos, porém, o conceito de totalidade não deve ser abandonado completamente. Para o autor, o reverso da tirania da totalidade pode ser a ditadura do fragmento. Citando Best (1989, p.361), indica a necessidade de algum conceito de totalidade positivo e normativo para contrabalançar a ênfase 
pós-estruturalista/pós-moderna na diferença e descontinuidade, caso contrário, estaremos abandonados à serialidade do individualismo pluralista e à supremacia dos valores competitivos contra a vida comunal, tão nocivos a qualquer projeto de sociedade e de educação. Mclaren defende um abandono ao uso redutor de totalidade e não o conceito de totalidade em si. O que necessita ser reafirmado, segundo o autor, não é o conceito de totalidade de uma unidade orgânica hegeliana, unificada e repressora, mas ao contrário, um sistema de relações e estrutura de diferença sobredeterminado, sem o qual não se pode compreender a diferença, como contradições sociais, como diferença em relação em vez de diferença como livre-flutuante e deslocada ao acaso. Sistemas de diferenças sempre envolvem padrões de dominação e relações de opressão e exploração. Segundo Mclaren, precisamos nos deter a economias de relações de diferença dentro de totalidades historicamente específicas que sempre estão abertas à contestação e à transformação. Como estruturas de diferença são sempre instáveis e múltiplas, as relações de totalidades opressoras(social, econômica, política, legal, cultural, ideológica) podem sempre ser desafiadas, dentro de uma pedagogia de libertação. Essas formas de totalidades não devem ser confundidas com a noção de metanarrativas universais de Lyotard. A concepção de metanarrativas deve ser rejeitada quando for utilizada injusta e opressivamente como garantias globais totalizantes e inclusivas para pensamento e ação que atendam a manutenção de regimes de verdade opressores. Porém, necessitamos reter algum tipo de base moral, ética e política, a partir das quais seja possível negociar os múltiplos interesses sociais. A crítica pós-moderna de resistência repudia a necessidade ou escolha de qualquer narrativa mestra, porque nelas se encontra apenas uma esfera pública, um único valor, uma só concepção de justiça que triunfa sobre as outras. O pós-modernismo de resistência sugere, ao contrário, que "esferas diferentes" devam conviver mutuamente. Isso não significa o condensamento de uma polpa cultural homogênea, mas de uma concepção mais plural de justiça, política, ética e estética. A questão crucial é a de totalidade, na medida em que o argumento contra uma única grande narrativa. Mclaren admite a existência de um metadiscurso primário, que poderia, na realidade, 
oferecer um engajamento provisório com discursos do Outro de uma maneira que seja unificadora sem ser dominadora e que possa orientar discursos suplementares. Esse discurso seria, por exemplo, a narrativa metacrítica dos direitos e da liberdade.

Mclaren cita Peter Murphy (1991, p.126), para diferenciar um discurso matriz de um metadiscurso. Murphy argumenta que um discurso matriz deseja se impor sobre todos ou outros discursos, por exemplo: isto é progressista, eles são reacionários, isto é o certo, eles estão errados. Um metadiscurso, por outro lado, busca compreender a sociedade enquanto uma totalidade, porém, sendo considerada com um todo complexo e contraditório, não um todo harmonioso do pensamento clássico, mas um todo difícil, multidimensional e pluralizado. É preciso estar comprometido com a compreensão desse conceito de um "todo difícil" (Charles Jencks, 1991), onde a verdade não se encontra em parte alguma, mas na sua totalidade ou nas implicações com a totalidade e seus fragmentos, referências e abordagens.

Essa concepção, ou resgate da totalidade, é um modo de questionamento que busca compreender como a crítica pós-moderna lúdica atende a uma estratégia de contenção do político, ao privilegiar formas "locais" de análise que centram o sujeito na experiência, como um local de verdade arquimediano e posiciona a ideologia como o único "leitor" da experiência. Mclaren tenta apontar para a existência de uma lógica de dominação subjacente, no interior das práticas de significação que constituem os produtos culturais do capitalismo tardio e, por essa razão, posiciona-se contra a rejeição do pós-modernismo lúdico de o conhecimento ser integrador e político devido a sua suposta incomensurabilidade de fenômeno cultural, político e econômico. Também revela que a diferença não é uma condição inerente à textualidade, mas um efeito histórico sobredeterminado socialmente que adquire a sua discursividade apenas no interior de modos de inteligibilidade cultural e historicamente dados. No espaço do pós-modernismo lúdico da textualidade, as relações sociais de produção são posicionadas não como historicamente necessárias, mas como sujeitas às leis do acaso e da contingência. Nessa desconstrução lúdica, o acaso e a contingência desempenham o mesmo papel ideológico que a diferença "nativa" (misteriosa, aleatória e não lógica) desempenha nos discursos tradicionais 
do humanismo. Ambos posicionam um campo social além do alcance da lógica da necessidade e da história.

As contribuições de Mclaren, ou melhor, o contrapeso de um multiculturalismo crítico, está longe de ser resposta às nossas angústias pedagógicas num mundo tão relativizado pelo pós-modernismo, porém, suas inquietações podem auxiliar nossas leituras, seguindo as pistas deixadas por outros tantos, que não aceitam de forma tão passiva a tirania das contingências.

\section{Notas}

${ }^{1}$ Artigo publicado inicialmente na Revista Espaço (INES-RJ) v. 1, n.17, p.26-28, Jul/2002 e publicado aqui com autorização do autor.

Doutor em Educação Física; Professor Assistente do Departamento de Didática da Faculdade de Educação -UFRJ.e-mail: macs2006@gmail.com

\section{Referências}

ARONOWITZe GIROUX. Postmodern Education. Mineapolis: University of Minnesota Press, 1991.

EBERT, T. Writing in the political: resistance (pos)modernism. Legal Studies Fórum XV (4):291-303,1991.

MCLAREN, P. Multiculturalismo crítico.ABSTRACT, São Paulo: Cortez, 1997. 
The post-modern trends in search for repaying - the balance of critical multi-culturalism

\begin{abstract}
In hopeless times it is important to get away from pessimisms, moreover, it is equally necessary to differenciate criticisms from the pedagocical romanticism. The contact with difficulties between theories and educational practices, together with doubtful economical policies in the social field, certainly leaves enougt room for recontextualization to come up as a rather dangerous tendency. This way, to consider the multicultural curricular approach as the solution is a blunder that should be avoided. Peter Mclaren's contribuitions certainly lead us to other challenges, such as a more critical understanding of the post-modern pedagogical tendencies, in which the public policies have relied on for some time. It may also be taken as a reference in the construction of critical educational policies.
\end{abstract}

Keywords: multiculturalism, post-modern, educational policies.

Solicitado em jul. 2008

Aceito em jul. 2008 
